\title{
Transcriptional changes in powdery mildew infected wheat and Arabidopsis leaves undergoing syringolin-triggered hypersensitive cell death at infection sites
}

\author{
Kathrin Michel · Olaf Abderhalden • \\ Rémy Bruggmann · Robert Dudler
}

Received: 12 January 2006/ Accepted: 26 June 2006/Published online: 29 August 2006

(C) Springer Science+Business Media B.V. 2006

\begin{abstract}
Blumeria graminis f.sp. tritici, the causal agent of powdery mildew in wheat, is an obligate biotrophic fungus that exclusively invades epidermal cells. As previously shown, spraying of a solution of syringolin A, a circular peptide derivative secreted by the phytopathogenic bacterium Pseudomonas syringae pv. syringae, triggers hypersensitive cell death at infection sites in powdery mildew infected wheat. Thus, the fungus is essentially eradicated. Here we show that syringolin A also triggers hypersensitive cell death in Arabidopsis infected with the powdery mildew fungus Erysiphe cichoracearum. To monitor transcriptional changes associated with this effect, we cloned 307 cDNA clones representing 158 unigenes from powdery mildew infected, syringolin A sprayed wheat leaves by a suppression subtractive hybridization cloning procedure. These cDNAs were microarrayed onto glass
\end{abstract}

Electronic Supplementary Material Supplementary material is available to authorised users in the online version of this article at http://dx.doi.org/10.1007/s11103-006-9045-7.

Kathrin Michel, Olaf Abderhalden and Robert Dudler contributed equally to this work. Wheat experiments were performed by Olaf Abderhalden, Arabidopsis experiments by Kathrin Michel

K. Michel · O. Abderhalden · R. Bruggmann

R. Dudler $(\bowtie)$

Institute of Plant Biology, University of Zurich,

Zollikerstrasse 107, CH-8000 Zurich, Switzerland

e-mail: rdudler@botinst.unizh.ch

Present Address:

R. Bruggmann

Institute for Bioinformatics, GSF Research Center for

Environment and Health, Munich Information Center for

Protein Sequences (MIPS), D-85764 Neuherberg, Germany slides together with 1088 cDNA-AFLP clones from powdery mildew-infected wheat. Microarray hybridization experiments were performed with probes derived from leaves, epidermal tissue, and mesophyll preparations of mildewed or uninfected wheat plants after syringolin A or control treatment. Similar experiments were performed in Arabidopsis using the Affymetrix ATH1 whole genome GeneChip. The results indicate a conserved mode of action of syringolin A as similar gene groups are induced in both species. Prominent groups include genes associated with the proteasomal degradation pathway, mitochondrial and other heat shock genes, genes involved in mitochondrial alternative electron pathways, and genes encoding glycolytic and fermentative enzymes. Surprisingly, in both species the observed transcriptional response to syringolin A was considerably weaker in infected plants as compared to uninfected plants. The results lead to the working hypothesis that cell death observed at infection sites may result from a parasite-induced suppression of the transcriptional response and thus to insufficient production of protective proteins necessary for the recovery of these cells from whatever insult is imposed by syringolin $\mathrm{A}$.

Keywords Blumeria graminis · Erysiphe cichoracearum $\cdot$ Hypersensitive response $\cdot$ Microarray · Pseudomonas syringae

\section{Introduction}

Powdery mildew is an agronomically important disease of wheat (Triticum aestivum L.) that is caused by the obligate biotrophic fungus Blumeria graminis f.sp. 
tritici. In a compatible interaction, conidiospores germinate and exclusively penetrate the wall of epidermal cells by formation of an appressorium and establish a haustorium, a specialized feeding structure surrounded by the invaginated plasmalemma of the colonized cell. Further growth occurs epiphytically by secondary hyphae, which complete the asexual cycle by formation of conidiophores after a few days. Race specific resistance of wheat to powdery mildew, often accompanied by the hypersensitive reaction (HR), is governed by the $P m$ resistance genes, the first of which has recently been cloned (Yahiaoui et al. 2004).

We previously observed that application of syringolin A (sylA), a compound produced by Pseudomonas syringae pv. syringae, not only induced acquired resistance to powdery mildew when sprayed onto wheat leaves before inoculation with powdery mildew, but essentially eradicated the fungus if sprayed two days after infection as an aqueous solution in the micromolar range (Wäspi et al. 2001). SylA is an unusual hydrophilic peptide that is secreted. It consists of a 12-membered ring formed by the two nonproteinogenic amino acids 5-methyl-4-amino-2-hexenoic acid and 3,4-dehydrolysine. The $\alpha$-amino group of the latter is connected by a peptide bond to a valine that in turn is linked to a second valine via a urea moiety (Wäspi et al. 1998a). SylA is synthesized by a mixed non-ribosomal peptide synthetase/polyketide synthetase whose corresponding genes we recently cloned (Amrein et al. 2004). SylA is the major form of a family of closely related structural variants which are likely produced by the same synthetase (Wäspi et al. 1999). Its synthesis is under the control of the gacA/ gacS global regulator (Reimmann et al. 1995; Wäspi et al. 1998a) that also controls pathogenicity and phytotoxin production (Hrabak and Willis 1992, 1993).

SylA does not have visible phytotoxic effects when sprayed onto wheat leaves at the concentrations used (40-100 $\mu \mathrm{M})$, nor could any antibiotic or fungitoxic activity be demonstrated (Wäspi et al. 2001). The curative effect of spraying sylA solutions on powdery mildew-infected wheat leaves was shown to be accompanied by induction of hypersensitive cell death at infection sites that can be visualized as whole-cell autofluorescence and the inability of corresponding cells to be plasmolysed (Wäspi et al. 2001). Thus, sylA was hypothesized to directly or indirectly reprogram colonized host cells to undergo hypersensitive cell death in a compatible interaction (Wäspi et al. 2001).

In order to better understand this effect of sylA at the molecular level, we decided to monitor transcriptional changes accompanying the HR triggered upon sylA spraying of powdery mildew infected plants. Here we report on the differential cloning of $307 \mathrm{cDNAs}$ from RNA of sylA treated powdery mildew-infected wheat leaves that could be grouped into 158 "unigenes" which were microarrayed onto glass slides together with 1088 cDNA-AFLP clones originating from another project aimed at cloning of powdery mildew-induced genes in wheat (Bruggmann et al. 2005). We report the results of microarray hybridization experiments performed with probes derived from whole leaves as well as from epidermal and mesophyll preparations of sylA and control treated wheat plants that where or were not infected with powdery mildew at various time points after treatment. In addition we show that sylA application on Arabidopsis infected with the powdery mildew fungus Erysiphe cichoracearum also induced hypersensitive cell death at infection sites. Thus, sylA induced genome-wide transcriptome changes in both infected and uninfected Arabidopsis were monitored using Affymetrix ATH1 whole genome gene chips. The results are discussed in the frame of a model about syringolin A action we derived from the results.

\section{Material and methods}

Plant and fungal growth conditions and treatment

Plants of the susceptible wheat (Triticum aestivum L.) cultivar Fidel were grown on standard soil (Einheitserde Type ED 73, Buchenberg, Germany) in pots of $12 \mathrm{~cm}$ diameter in a growth chamber $(16 \mathrm{~h}$ light period at $22^{\circ}, 8 \mathrm{~h}$ dark period at $18^{\circ} \mathrm{C} ; 60 \%$ relative humidity). Seven-day-old plants were used for all experiments. A Swiss field isolate of the powdery mildew fungus Blumeria graminis f.sp. tritici (Reckenholz accession \#92315) was maintained on the wheat cultivar Fidel by weekly transfer to new plants. Inoculations were performed at a density of 100150 conidia $/ \mathrm{mm}^{2}$ by brushing plants infected one week earlier over the test plants. Plant material was collected from different tissues at various time points after infection.

Arabidopsis (ecotype Columbia) was grown in standard soil after stratification at $4^{\circ} \mathrm{C}$ for 3 days with a $16 \mathrm{~h}$ photoperiod $\left(100-150 \mu \mathrm{mol} \mathrm{m}^{-2} \mathrm{~s}^{-1}\right)$ at $21^{\circ} \mathrm{C}$. Twelve to 14 day-old plants were used for experiments. A virulent strain of Erysiphe cichoracearum that was isolated from a fortuitously infected Arabidopsis (ecotype Columbia) plant growing in a climate chamber at our Institute was used throughout the studies. The taxonomic identification was performed by Prof. R. Honegger, Institute of Plant Biology, University of 
Zurich, on the basis of the 18S RNA sequence and specific morphological characteristics such as conidiophore foot cells and septation. The fungus was maintained on 3-4 week-old Arabidopsis (ecotype Columbia) plants by weekly transfer to new plants. Inoculation was performed in a chamber by slightly dapping heavily infected leaves on the surface of rosette leaves. After inoculation, plants were transferred to a growth chamber, covered with a plastic lid for $12 \mathrm{~h}$, and kept under the conditions given above. For Affymetrix ATH1 gene chips hybridization experiments, leaves of 14-day-old plants were infected to a density of $150-200$ spores $/ \mathrm{mm}^{2}$ as quantified by spore counting.

\section{Microscopy}

Arabidopsis leaves were destained by overnight immersion in a 1:2 (v/v) dilution of a lacto-phenol stock solution (phenol:lactic acid:glycerol:water 1:1:2:1) with ethanol at room temperature. Fungal structures were stained with coomassie blue $(0.3 \%(\mathrm{w} / \mathrm{v}))$ in a $1: 1$ mixture of water and methanol for $1 \mathrm{~min}$ and cleared immediately in sterile water. Leaf segments were mounted onto microscopic slides in $40 \%(\mathrm{v} / \mathrm{v})$ glycerol. Microscopic inspection with an Axioplan microscope (Carl Zeiss AG, Oberkochen, Germany) was done by bright-field or blue light incident fluorescence microscopy (excitation filter $450-490 \mathrm{~nm}$; bypass filter 515 $565 \mathrm{~nm})$. Images were captured with the Magna Fire 2.0 digital camera (Optronics, Goleta (CA), USA) using auto exposure settings.

Isolation of sylA and plant treatment

Syringolin A (sylA) was isolated from still cultures of Pseudomonas syringae pv. syringae strain B301D-R as previously described (Wäspi et al. 2001). SylA treatment of infected plants was carried out $48 \mathrm{~h}$ after inoculation. Pots were placed on a rotating platform and sprayed with $10 \mathrm{ml}$ of distilled water containing $100 \mu \mathrm{M}$ (for wheat treatments) or $20 \mu \mathrm{M}$ sylA (for Arabidopsis) and $0.05 \%(\mathrm{v} / \mathrm{v})$ Tween 20 or a control solution (0.05\% Tween 20). Cyprodinil (Novartis AG, Basel, Switzerland) was kindly provided by Dr. M. Oostendorp (Novartis Crop Protection AG, Basel, Switzerland). The substance was dissolved in an 8:2 $(\mathrm{v} / \mathrm{v})$ water/acetone mixture at a concentration of $888 \mu \mathrm{M}$ and sprayed as described above. Control plants were sprayed with the solvent only.

For wheat experiments, plant material was collected from different tissues at various time points after treatment. For differential screening, whole seedlings were harvested. For microarray experiments, only primary leaves were harvested. In certain experiments, the abaxial epidermis was stripped off the leaf using a scalpel and a pair of tweezers. Stripped off epidermis, the remainder of the leaf ("mesophyll" preparation), and other plant material was immediately frozen in liquid nitrogen until further use. For Arabidopsis experiments, primary leaves were harvested.

RNA extraction and suppression subtractive hybridization (SSH) cDNA cloning from wheat

RNA was isolated from collected plant material that was ground to a fine powder in liquid nitrogen using mortar and pestle. The material was suspended in a 1:1 mixture of phenol and $2 \times \mathrm{NETS}(200 \mathrm{mM} \mathrm{NaCl}, 2 \mathrm{mM}$ EDTA, $20 \mathrm{mM}$ Tris-HCl, 1\% SDS, $\mathrm{pH} 7.5$ ) that was preheated to $80^{\circ} \mathrm{C}$. Poly $(\mathrm{A})^{+} \mathrm{RNA}$ was isolated from $200 \mu \mathrm{g}$ to $1000 \mu \mathrm{g}$ of total RNA using oligo(dT) OLIGOTEX $^{\circledR}$ (Qiagen, Basel, Switzerland). cDNA subtraction and differential screening was carried out according to Diatchenko et al. (1999) by using the PCR-Select ${ }^{\mathrm{TM}}$ cDNA subtraction kit (Clontech Laboratories Inc., Mountain View, CA, USA). Total RNA of the 2 hat and 6 hat time points as well as of the 12 hat and 24 hat time points, respectively, was combined at a ratio of $1: 1(\mathrm{w} / \mathrm{w})$ prior to $\operatorname{poly}(\mathrm{A})^{+}$RNA isolation. To minimize variation, experiments were repeated twice and total RNA was combined at a ratio of 1:1 (w/ w). Forward and reverse subtractions were carried out with $2 \mu \mathrm{g}$ of $\operatorname{poly}(\mathrm{A})^{+}$RNA. For cDNA digestion, $R s a \mathrm{I}$ restriction endonuclease was obtained from Roche Applied Science (Penzberg, Germany). First and second hybridizations lasting $10 \mathrm{~h}$ and $18 \mathrm{~h}$, respectively, were carried out at $68^{\circ} \mathrm{C}$. The $\mathrm{BD}$ Advantage $\mathrm{e}^{\mathrm{TM}}$ 2 Polymerase Mix (Clontech Laboratories Inc., Mountain View (CA), USA) was used for hot start PCR amplification of recombinant cDNA hybrids. The first PCR included 27 rounds of amplification and the second PCR included 10 rounds of amplification. All cDNA inserts obtained by SSH contained upstream NstPrm1 (5'-TCGAGCGGCCGCCCGGGCAGGT) and downstream NstPrm2R(5'-AGCGTGGTCGCG GCCGAGGT) adaptor sequences used for PCR.

\section{Differential screening}

The cDNA pool obtained in the forward subtraction was differentially screened as described by Diatchenko et al. (1999) using the PCR-Select Differential Screening kit (Clontech Laboratories Inc., Mountain View, CA, USA). PCR products were purified using 
GFX spin columns (Pharmacia, Uppsala, Sweden), subcloned into pCRII-TOPO (Invitrogen BV, Groningen, The Netherlands) and transformed into E. coli TOP $10 \mathrm{~F}^{\prime}$ following protocols of the TOPO TA cloning kit (Invitrogen BV, Groningen, The Netherlands). cDNA inserts of single colonies grown in liquid cultures in 96-well microtiter plates were amplified by PCR. Five $\mu$ l of PCR reactions were diluted in $440 \mu \mathrm{l}$ of $0.2 \mathrm{M} \mathrm{NaOH}$ and quadruplicate cDNA dot blots were prepared by blotting $100 \mu \mathrm{l}$ DNA dilution onto nylon membranes (Hybond-XL, Amersham Biosciences, Uppsala, Sweden) using a MilliBlot-D vacuum blotting manifold (Micropore Corp., Bedford, MA, USA). ${ }^{32}$ P-radioactively labeled probes were prepared from $60 \mathrm{ng}$ of DNA corresponding to the forward and reverse-subtracted cDNA pools and from $100 \mathrm{ng}$ of dscDNA corresponding to sylA-treated and untreated samples according to standard procedures (Maniatis et al. 1982). Probes equalized for radioactivity were hybridized to the dot blots for $1 \mathrm{~h}$ at $72^{\circ} \mathrm{C}$ using Express Hyb buffer (Clontech Laboratories Inc., Mountain View, CA, USA). After washing, membranes were exposed to Kodak Biomax MS films (Kodak, New Haven, USA).

Sequence analysis

Sequencing was performed on an ABI 377 instrument (Applied Biosystems, Foster City, USA). Bioinformatic analyses were performed with the Staden Software Package (Staden 1996), the Wisconsin Package Version 10.3 (Accelrys Inc., San Diego, CA, USA), and the Advanced Blast internet service provided by EMBnet (http://www.ch.embnet.org/).

Wheat microarray hybridization and data normalization

Design and fabrication of the cDNA microarrays used in this study are described in Bruggmann et al. (2005). Indirect labeling (Randolph and Waggoner 1997; Hughes et al. 2001) of probes with fluorescent dyes Alexa Fluor 555 and Alexa Fluor 647 (Molecular Probes Inc., Eugene, OR, USA) and hybridization were carried out as described (Bruggmann et al. 2005), except that $2 \mu \mathrm{g}$ of total RNA was used as starting material for the amplification with the MessageAmp aRNA-Kit (Ambion, Cambridgeshire, UK). In vitro transcription was carried out for $15 \mathrm{~h}$ using 21-mer oligo-dT in all indirect labeling reactions.

Slides were scanned twice at the two characteristic wavelengths with the G2505B microarray scanner (Agilent Technologies Inc., Palo Alto, CA, USA) at
$100 \%$ laser power and $100 \%$ photo multiplier gain setting at a resolution of $10 \mu \mathrm{m} /$ pixel. Fluorescence signal strength was acquired with the ImaGene 4.2 software (BioDiscovery Inc, El Segundo, CA, USA) using fixed cycle segmentation with the following cut off settings: Signal low 0.1; signal high 0.95; background buffer low 0; background buffer high 0.8 and acquisition settings: Background buffer 4 pxls; background width 20 pxls. Individual net spot intensities were calculated by subtracting the average fluorescence signal obtained from the background area off the average fluorescence signal obtained in the spot area. $t / c$ ratios were calculated by dividing net spot intensities derived from the test hybridization by net spot intensities derived from the control hybridization.

Data normalization, which was permanently monitored on MA-plots (Dudoit et al. 2002) using the ORIGIN 7.0 software (OriginLab Corp., Northhampton, MA, USA), proceeded in three steps: (1) Signal intensities of replicated probes on the same slide were integrated by calculating the average logged signal intensity of unflagged replicates. (2) Centering of $\log$ (ratios) around zero was achieved by iterative $\log$ (ratio) mean centering (ILMC) as implemented in TIGR MIDAS V2.20 software (Saeed et al. 2003) using a mean centering data range setting of \pm 1.0 standard deviation. (3) High and low signal intensity cut off values were applied. The upper limit was set to 55,000 units, the lower limit was set to twice the median of net signal intensities obtained for empty water control spots. If required, cut off limits were adjusted when indicated by MA-plot inspection. Signal intensities of spots outside limits were set to the respective cut off value. If required, data were leveled by between-slide standard deviation regularization (TIGR MIDAS V2.20 software Saeed et al. 2003) in order to balance for technical and biological variations (Yang et al. 2002). Differentially expressed genes were identified by one-sample $t$-test statistics (Dudoit et al. 2002) using the TIGR MIDAS V2.20 software (Saeed et al. 2003).

\section{Microarray data verification with RT-PCR}

The reverse transcription reaction was performed with $10 \mu \mathrm{g}$ RNA extracted from wheat treated with $100 \mu \mathrm{M}$ sylA or the control solution at the 12 hat timepoint using the Superscript ${ }^{\mathrm{TM}}$ II RNase Reverse Transcriptase kit (Invitrogen, Basel, Switzerland) according to the instructions of the manufacturer. PCR was carried out in a $20 \mu \mathrm{l}$ volume containing $1 \mu \mathrm{l} \mathrm{cDNA}$-template $(0.5-1 \mu \mathrm{g}), 2 \mu \mathrm{l}$ of $1 \mathrm{mM}$ dNTP mix, $0.4 \mu \mathrm{l}$ of each primer $(10 \mu \mathrm{M}), 1 \times$ reaction buffer and 1 unit Taq 
polymerase (Sigma-Aldrich, Buchs SG, Switzerland). The thermocycling conditions were: $94^{\circ} \mathrm{C} 3 \mathrm{~min},\left[94^{\circ} \mathrm{C}\right.$ $45 \mathrm{~s}$, annealing temperature $\left.45 \mathrm{~s}, 72^{\circ} \mathrm{C} 60 \mathrm{~s}\right] \times 25$ 30 cycles, $70^{\circ} \mathrm{C} 10 \mathrm{~min}$. PCR reactions were separated on a $1.5 \%$ agarose gel. The primers used are given in supplementary Table S4.

Arabidopsis ATH1 whole genome chip hybridization experiments

RNA was extracted by homogenizing 50-100 mg plant material with an electrical homogenizer in $750 \mu \mathrm{l}$ Trizol extraction buffer (Invitrogen BV, Groningen, Netherlands) and purified with the RNeasy Kit (Qiagen, Basel, Switzerland) according to the protocols of the manufacturer. The integrity of RNA used for gene chip hybridization experiments was checked on a bioanalyzer (Agilent Technologies, Inc., Palo Alto, CA, USA). For the preparation of probes, double stranded cDNA was synthesized with the SuperScript kit (Invitrogen, Basel, Switzerland) using 15-20 $\mu \mathrm{g}$ total RNA and purified with the Affymetrix GeneChip Cleanup module (Affymetrix, Bucks, UK). Probes were labeled using the Ambion MEGA Script T7 kit (Ambion, Huntingdon, UK) and again purified with the Affymetrix GeneChip Sample Cleanup module. Fragmentation of the labeled RNA and ATH1 chip hybridizations were performed according to the technical manual provided by Affymetrix (Affymetrix, Bucks, UK; http://www.affymetrix.com/support/technical/manual/expression_manual.affx). Three independent biological replicates were performed for all experiments.

The Affymetrix Microarray Suite program 5.0 was used to summarize the probe intensities to expression values (Hubbell et al. 2002) and to calculate the algorithm absolute call flag $\mathrm{P}$ (present), $\mathrm{M}$ (marginal), and A (absent) (Liu et al. 2002). The data were analyzed with the GeneSpring version 7.0 program (Silicon Genetics, San Carlos, CA). Normalization was performed by using a per-chip 50th percentile method that normalizes the values of each chip to the individual median value, allowing comparison among chips. Subsequently, a per-gene normalization was performed which normalizes the expression values for each gene to their respective median throughout all samples. For each gene, the so-called control strength value $C$ was calculated by multiplying the respective per-gene and the per-chip normalization factor (i.e. median value). Genes with low control value $\mathrm{C}$ were omitted from consideration. Statistical analyses were performed on normalized log values. Differentially expressed genes were identified by computing two-sample Welch's $t$-test statistics based on variances calculated by Genespring's Cross Gene Error Model (Rocke and Durbin 2001). In addition, the Benjamini and Hochberg False Discovery Rate Multiple Testing Correction option was applied (Benjamini and Hochberg 1995). Genes that exhibited a larger than 2-fold difference in their signal values between control and treatment with a $p$ value $<0.05$ were extracted. The microarray data can be accessed in a MIAME-compliant form through the ArrayExpress database (http://www.ebi.ac.uk/arrayexpress/) under the accession number E-MEXP-739.

\section{Results}

Identification of syringolin A-induced wheat genes and isolation of corresponding cDNAs

Seven-day-old seedlings of winter wheat (Triticum aestivum $c v$. Fidel) were infected at high spore density with a highly virulent Swiss field isolate of wheat powdery mildew (Blumeria graminis f.sp. tritici). Fortyeight hours after infection, the plants were sprayed with a $100-\mu \mathrm{M}$ solution of syringolin A (referred to as sylA for simplicity) or a control solution. Primary leaves were harvested $2 \mathrm{~h}, 6 \mathrm{~h}, 12 \mathrm{~h}$, and $24 \mathrm{~h}$ after sylA treatment. Total RNA was extracted and two pools representing two time points each were created by combining equal amounts of total RNA from the $2 \mathrm{~h}$ and $6 \mathrm{~h}$ (pool A) and the $12 \mathrm{~h}$ and $24 \mathrm{~h}$ (pool B) time points.

Suppression subtractive hybridization (Diatchenko et al. 1999) with control treated versus sylA treated RNA of pool A and pool B was carried out, whereby cDNA derived from control RNA was subtracted from cDNA derived from sylA-treated RNA. This should result in cDNA fragments representing mRNA species that accumulate after sylA treatment. Enriched cDNA fragments were amplified by PCR and cloned. The reverse subtraction was also performed but not analyzed in detail as it was expected and confirmed to yield mainly fungal cDNAs because of the large fungal biomass on control leaves as compared to sylA-treated leaves. Subtraction efficiency was monitored by quantitative PCR amplification of wheat $\alpha$-tubulin transcripts, whose levels were assumed not to be affected by sylA treatment. Indeed, no $\alpha$-tubulin cDNA could be detected in both the forward and the reverse subtracted cDNA pool A, in contrast to the unsubtracted pools (data not shown).

From 498 of the 564 colonies $(50 \%$ each derived from pool A and pool B cDNA, respectively) that were grown in 96-well plates, cDNA fragments in a size 
range between $50 \mathrm{bp}$ and $3000 \mathrm{bp}$ (550 bp average) could be successfully amplified. These fragments were spotted in groups of 94 onto four sets of replicate nylon filters. Two sets were hybridized to equalized radiolabeled cDNA probes derived from sylA-treated test samples and buffer-treated control samples, respectively. The remaining duplicate arrays were hybridized to radioactively labeled forward- and reverse-subtracted cDNA probes in order to achieve enhanced display sensitivity (as proposed by Diatchenko et al. 1999). The 307 fragments which exhibited a stronger hybridization signal with sylA-treated probes than with control probes were sequenced. Sequence comparison to entries in public sequence databases resulted in the annotation of $76 \%$ of the sequences. For the remaining $24 \%$, similarity was insignificant. All sequences with similarity to proteins with a known particular putative function in the databases were put into a functional group. Sequence comparisons of the 307 cDNAs to each other allowed sequences within such a functional group with more than $98 \%$ identity over at least $100 \mathrm{bp}$ to be assembled into contigs. Thereby the 307 sequences were put into 158 "unigenes", each one represented by a contig containing 1 or more (up to 14) sequences. Sequences within a contig were usually of the same length, with an occasional longer sequence containing an internal RsaI site indicative of incomplete digestion during the cloning procedure. The sequence of one representative (the longest) of a contig was submitted to the EMBL nucleotide database. Sequences within a contig exhibited highly consistent hybridization signals in the dot blot hybridization experiments described above (data not shown). Of the 158 unigene sequences, $71(45 \%)$ exhibited $>90 \%$ sequence identity to ESTs present on the Affymetrix wheat gene chip in an overlap of at least $80 \mathrm{bp}$.

Analysis of syringolin A induced wheat transcript accumulation by microarray hybridization

In order to study the expression of genes corresponding to the $158 \mathrm{SSH}$ clones in a more versatile way, they were microarrayed in duplicate spots on glass slides along with 1088 cDNA-AFLP clones originating from another project aimed at cloning of powdery mildewinduced genes in wheat (Bruggmann et al. 2005). The design of the microarray, which also contained various control genes, was described elsewhere (Bruggmann et al. 2005).

Two pilot microarray hybridization experiments were carried out to define the time frame for further experiments. Wheat plants were or were not infected with powdery mildew and two days later sprayed with
sylA or the control solution. RNA was extracted from whole leaves of these plants $2 \mathrm{~h}$ and $24 \mathrm{~h}$ after treatment (hat), respectively. Fluorescently labeled probes derived from these RNA preparations were hybridized to single microarray slides. Few transcripts exhibited weak accumulation at the 2 hat time point in both infected and uninfected plants. In contrast, at the 24 hat time point a larger number of transcripts had accumulated to a greater extent, whereby this number appeared to be larger in uninfected than in infected plants (data not shown). Thus, we decided to perform further experiments in three biologically independent repetitions at the 8 hat, 12 hat and 24 hat time points with both infected and uninfected plants. In one repetition of each experiment the fluorescent dyes of control and sylA-treated probes were switched. Because the HR after sylA treatment of powdery mildew-infected plants occurs almost exclusively in colonized epidermal cells, it was of interest to determine whether transcripts accumulated in an epidermisspecific way. Thus, the hybridization probes from the 8 hat timepoint were prepared from stripped abaxial epidermis and the remainder (dubbed "mesophyll" preparation for simplicity, although the adaxial epidermis was still present) of infected leaves. In order to assess epidermis specificity of gene expression, the contamination of epidermis preparations with mesophyll cells was estimated by using the ribulose-1,5bisphosphate carboxylase (rubisco) gene, which is exclusively expressed in cells possessing chloroplasts, as a mesophyll marker. An epidermis specificity factor ES was calculated by dividing the hybridization signal intensity ratio of a particular target obtained with the epidermis- and mesophyll-derived probes, respectively, by the equivalent ratio obtained for the rubisco target. Thus, an ES value of $\geq 2$ (significantly greater than 1 ) for a particular target was taken to indicate that accumulation of the respective transcripts predominantly occurred in the epidermis (Bruggmann et al. 2005).

The average of normalized hybridization signals was taken over the three repetitions of all experiments and over all copies of cDNAs present on the microarray. MA-plots (Dudoit et al. 2002) of averaged normalized data from the 12 hat and the 24 hat timepoints are shown in Fig. 1. Transcripts were considered to alter significantly in abundance if the average hybridization signal ratio (treatment/control; $t / c$-ratio) was $\geq 2$ or $\leq 0.5$ with an error probability of $p<0.05$ (Student's test). The $100 \mathrm{cDNAs}$ with $\mathrm{t} / \mathrm{c}$-ratios meeting this criterion at least at one of the sampled time points are listed in supplementary Table S1.

Inspection of Table S1 reveals that sylA treatment lead to an increase in the abundance of 95 transcripts. 

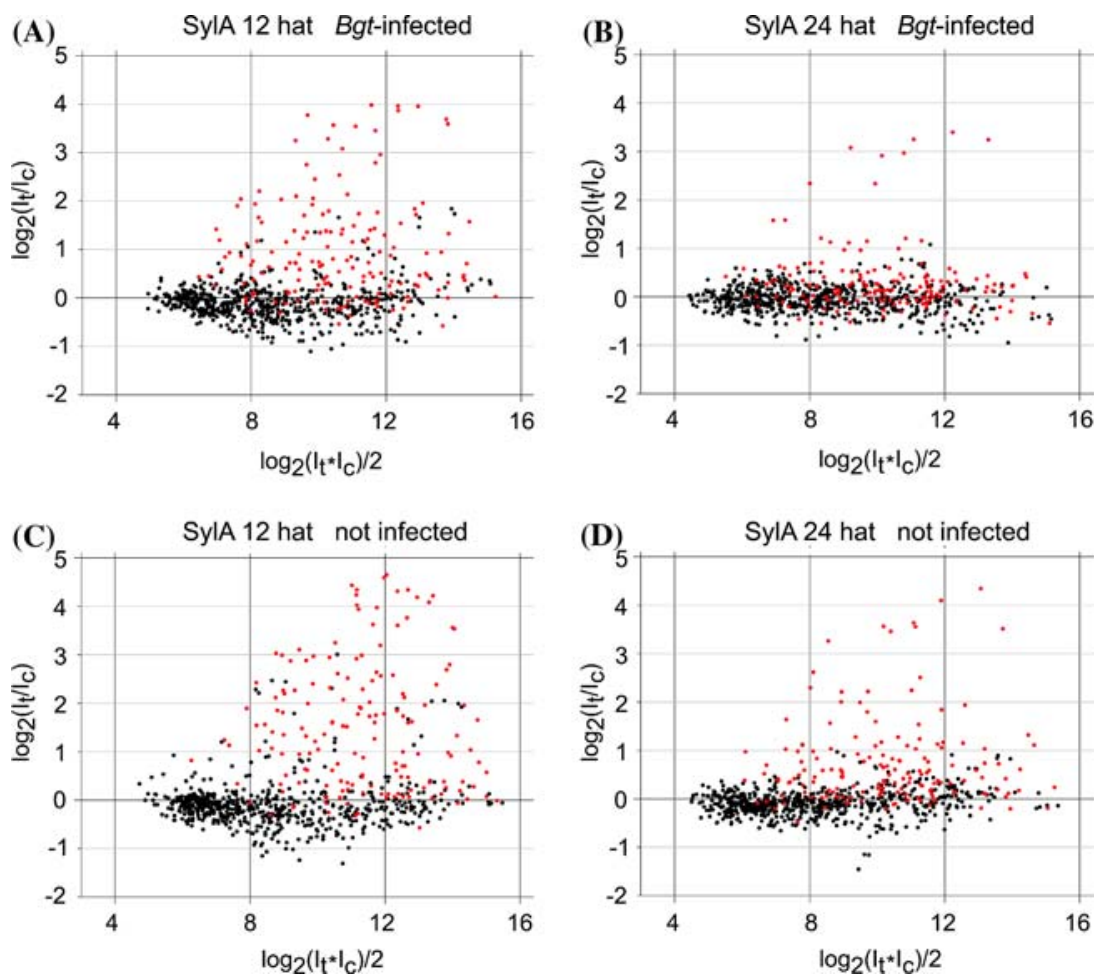

Fig. 1 Microarray analysis of sylA-induced wheat transcript accumulation. The MA-plots visualize average $t / c$ ratios of three biologically repeated experiments. Red dots represent $\mathrm{SSH}$ derived clones obtained in this work. Black dots represent cDNA-AFLP clones derived from wheat leaves inoculated with barley powdery mildew, representing in part transcript accumulating

during this non-host interaction (Bruggmann et al. 2005). Hybridization probes were derived from powdery mildewinfected $(\mathbf{A}, \mathbf{B})$ or uninfected $(\mathbf{C}, \mathbf{D})$ leaf material collected $12 \mathrm{~h}(\mathbf{A}, \mathbf{C})$ and $24 \mathrm{~h}(\mathbf{B}, \mathbf{D})$ after spraying with $100 \mu \mathrm{M}$ sylA or control buffer, respectively

Of these, 93 were detected with probes derived from RNA extracted from whole leaves. Highest foldinduction values were in most cases observed at the 12 hat timepoint in uninfected leaves. In infected leaves, t/c-ratios were lower by an average factor of $0.60 \pm 0.15$, which is significantly different from 1 $(p<0.001$; one-sample $t$-test). Twenty-four hours after treatment, transcript levels had decreased in the majority of cases in both uninfected and infected plants, whereby $\mathrm{t} / \mathrm{c}$-ratios were $0.72 \pm 0.18$-fold lower in infected as in infected leaves, still significantly different from $1(p<0.001)$. The set of genes induced more than 2-fold by sylA application on infected plants was a subset of SylA induced genes in uninfected plants at the 12 and 24 hat timepoints, i.e. no transcript was found to accumulate exclusively after sylA treatment of infected leaves. This could have resulted in principle from a weak background accumulation of sylA-induced gene transcripts caused by powdery mildew infection alone. To check if this was the case, plants that were or were not inoculated with powdery mildew were sprayed with the control buffer and epidermis and mesophyll tissue was sampled $8 \mathrm{~h}$ later. A single hybridization experiment was performed in

which signals of probes from infected and uninfected tissue were directly compared for both epidermis and mesophyll preparations. Of all sylA-affected transcripts, only three accumulated significantly after inoculation with the compatible pathogen: RB_10.1 (gigantea; epi 6.6, meso 3.4), OA_a1B08 (BCS1-like protein; epi 6.3, meso 3.0), and RB_327.1 (putative immediate-early salicylate-induced glucosyltransferase; epi 6.1, meso 10.9). The average ratio of hybridization signals of all other sylA-induced genes listed in Table S1 was $1.07 \pm 0.40$ in the epidermis and $1.07 \pm 0.33$ in the mesophyll. Thus, powdery mildewtriggered background accumulation of sylA-induced transcripts seems generally not to account for the apparent weaker response of infected tissue to sylA.

Of the 85 induced genes detected with probes derived from epidermal and mesophyll tissue of infected leaves, 83 were also in the set of induced genes detected with probes from whole leaves. With one possible exception (OA_b2E06, encoding a valyl-tRNA synthetase), none of these transcripts appeared to accumulate predominantly in the epidermis, as they exhibited ES values <2 (Table S1). In contrast, the TaGLP4 cDNA (accession no. AJ237942) which 
encodes a germin-like protein from wheat that was previously shown to be expressed exclusively in the epidermis (Schweizer et al. 1999; Bruggmann et al. 2005) exhibited an ES value of 7.9 (not listed in Table S1 because corresponding transcripts accumulate upon powdery mildew infection, but not sylA application). This shows that the ES data were reliable.

Although the SSH cloning procedure reported here was not aimed at transcripts whose levels were reduced upon sylA treatment for the reasons mentioned above, five genes with reduced transcript levels after sylA spraying were identified (Table S1). The respective clones belonged to the set of clones obtained in an earlier cDNA-AFLP cloning experiment aimed at powdery mildew-induced genes (Bruggmann et al. 2005).

Because spraying of sylA leads to the eradication of powdery mildew on wheat leaves, it was of interest to test to what extent killing of the fungus with a fungicide (200 ppm solution of cyprodinil) affected transcript levels of sylA-induced genes. SylA-induced genes were essentially not affected, as only four of them were also weakly induced by application of the fungicide, in addition to two genes unaffected by sylA (data not shown).

Verification of microarray data

Transcript accumulation was verified for a selection of nine genes that were strongly induced according to the microarray data using RT-PCR with gene-specific primers (supplementary Fig. S1).

SylA-induced gene transcripts in wheat

The 100 genes whose transcript levels were altered by sylA application were grouped according to biological and molecular function GO terms (Ashburner et al. 2000). Two thirds fell into the four largest groups: a group of 21 members involved in carbohydrate metabolism, a group containing 11 members encoding proteins involved in ubiquitin-dependent protein catabolism, a group with 11 members involved in the response to abiotic stimulus, and a group encompassing 19 members of unknown function.

A prominent group of sylA-induced transcripts encodes enzymes involved in carbohydrate metabolism. In addition to transcripts encoding putative sucrose degrading enzymes, transcripts encoding most enzymes involved in glycolysis are accumulating after sylA application, as are 3 transcripts encoding enzymes participating in the tricarboxylic acid (TCA) cycle (Table S1). However, the transcripts exhibiting the highest fold-induction within this group encoded two alcohol dehydrogenase (ADH) isozymes, thus indicating that sylA application triggered the alcoholic fermentation pathway.

Another prominent group of 11 transcripts accumulating after sylA action encode proteins associated with proteasomal protein degradation, including catalytic and regulatory subunits of the proteasome (Table S1). Although the proteasomal protein degradation pathway was shown to be involved in many aspects of plant life, including developmental and hormonal processes as well as pathogen resistance and senescence (reviewed by Tör et al. 2003; Vierstra 2003; reviewed by Moon et al. 2004; Smalle and Vierstra 2004), the proteasomal degradation machinery is in general not transcriptionally regulated in these processes. In animals, abundance of the proteasome was recently found to be regulated at the transcriptional level via an autoregulatory feedback mechanism (Meiners et al. 2003). Indicative of a similar mechanism in plants, transcription of Arabidopsis 26S proteasome subunits was upregulated in mutant lines expressing diminished levels of RPN10 or RPN12a (Yang et al. 2004). Thus, the observed sylA-induced accumulation of proteasomerelated transcripts may indicate a compensatory production of proteasome components lost due to sylA action, or, alternatively, it may reflect an increased demand of proteasome-mediated protein catabolism.

Five transcripts encoding heat shock proteins (HSPs) were identified that strongly accumulated after sylA treatment (Table S1). OA_a1H02 and OA_a1B01 exhibited over $90 \%$ sequence identity at the amino acid level to the wheat small heat shock proteins (sHsps) Hsp23.6 and Hsp23.5. Both sHsps belong to the mitochondrial class $\mathrm{M}$ but are encoded in the nucleus (Scharf et al. 2001). sHsps are thought to contribute to stress tolerance by binding to non-native proteins in stress situations to keep them from aggregating until refolding by other Hsps. In maize for example, mitochondrial sHsps were demonstrated to protect the NADH:ubiquinone oxidoreductase (Complex I) electron transport under saline stress conditions (Hamilton and Heckathorn 2001). Intriguingly, the three other sylA-induced transcripts in this class putatively encode two mitochondrial Hsp60 group I chaperonins (OA_a1E07 and OA_b1C09) and a DnaK-like mitochondrial Hsp70 chaperone (OA_a3B09). As these five transcripts were strongly induced (Table S1), accumulation of Hsps after sylA treatment may be particularly important in the mitochondria, perhaps indicating that mitochondria are particular targets of sylA action.

Indeed, apart from the Hsps mentioned above, a number of other putative proteins encoded by 
sylA-induced genes are likely also located in the mitochondrion in vivo. This includes the voltage dependent anion channel (VDAC; OA_b1F04), alternative oxidase 1 (AOX1, OA_a1E06), a probable external rotenone-insensitive $\mathrm{NAD}(\mathrm{P}) \mathrm{H}$ dehydrogenase-like protein $\left(O A \_a 2 B 11 ; 82 \%\right.$ amino acid similarity to Arabidopsis NDB2 in the 174 amino acid overlap), prohibitin (OA_a3CO3) and a BCS1-like ( $b c_{1}$ synthesis; OA_a1B08) protein. Of these, strongest accumulation was observed for VDAC and AOX (Table S1). Accumulation of transcripts corresponding to VDAC (synonym porin) is interesting because its involvement in the mitochondrial apoptotic pathway in animals (reviewed by Hengartner 2000). VDAC is encoded in the nucleus and the protein is located in the outer mitochondrial membrane where it forms the major membrane channel (Benz 1994) for metabolite exchange whose permeability depends on the membrane potential (Rostovtseva and Colombini 1997). In animals, VDAC participates in the regulation of apoptosis via interaction with pro- and anti-apoptotic factors of the Bcl-2 family (Shimizu et al. 2000; Banerjee and Ghosh 2004) or formation of the permeability transition pore complex (PTPC) (Crompton et al. 2002) and control of mitochondrial homeostasis and metabolism with respect to variable permeability to ATP (Lemeshko 2002; Lemeshko and Lemeshko 2004).

SylA application lead also to increased transcript levels of genes generally associated with the response to abiotic stress, in particular to detoxification (Table S1). Three of these code for ABC transporters, four for glutathione- $S$-transferases, and three for cytochrome P450 enzymes. Noteworthy is also the strong induction of transcripts encoding four $\alpha / \beta$ fold hydrolases, among them two homologs of the Pir7b esterase from rice (Wäspi et al. 1998b). In rice, Pir7b transcripts were found to strongly accumulate after sylA treatment or inoculation with sylA-producing $P$. syringae pv. syringae strains, but not after inoculation with sylA-negative mutants (Reimmann et al. 1995; Wäspi et al. 1998a). Of the two clones listed under "response to biotic stimulus", OA_a1E08 encodes a putative protein most similar to RPP8-like proteins from Arabidopsis, while OA_b2E04 encodes a protein with $83 \%$ identity in the 210 amino acid overlap region to the product of the DMI1 gene of Medicago trunculata. This gene, which encodes a putative ion channel and is highly conserved in angiosperms, was shown to be required for the response to Nod factors and symbiontic bacteria as well as for mycorrhizal symbiosis (Ané et al. 2004).

Notably absent among sylA-induced genes are many genes usually associated with the response to biotic stimuli, as e.g., PR genes and genes involved in secondary metabolism. Indeed, of the 141 transcripts found to accumulate in wheat upon inoculation with the inappropriate barley powdery mildew Blumeria graminis f.sp. hordei, which results in HR of the attacked cells (Bruggmann et al. 2005), only 27 (19\%) were also found to accumulate after sylA application alone (clone names marked in bold face in Table S1). Thus, there appears to be a relatively small overlap between sylAinduced genes and genes induced upon the interaction with an inappropriate powdery mildew fungus.

Of the five genes that were downregulated by sylA application (underlined in Table S1), two (RB_10.1 (gigantea), and RB_327.1 (putative immediate-early salicylate-induced glucosyltransferase); underlined bold face in Table S1) were upregulated after inoculation with the inappropriate $B$. graminis f.sp. hordei (Bruggmann et al. 2005) and also with the compatible forma specialis tritici.

SylA action on powdery mildew-infected Arabidopsis

Inoculation of 14-day-old Arabidopsis with conidiospores of a compatible isolate of E. cichoracearum lead to the emergence of elongating secondary hyphae on the leaf surface $36 \mathrm{~h}$ post inoculation (hpi), and sporulation occurred five days post inoculation (dpi). Spray application of a $20 \mu \mathrm{M}$ SylA solution 2 dpi lead to the complete arrest of fungal growth at nearly all infection sites. Arrest of fungal growth was accompanied with autofluorescence at infection sites (Fig. 2). Only in rare cases, an infection site showed no autofluorescence and the fungus continued growth. In contrast to wheat, autofluorescence was more pronounced in mesophyll cells underneath colonized epidermis cells, which generally exhibited weaker autofluoresence. Killing the powdery mildew fungus with the fungicide cyprodinil did not lead to autofluorescence at most infection sites (88\%). SylA application on uninfected Arabidopsis never caused a visible phenotype if concentrations below $40 \mu \mathrm{M}$ were employed. Slight yellowing of leaves became visible at concentrations above $100 \mu \mathrm{M}$. Thus, similar to what is observed in wheat, sylA application can convert a compatible interaction with powdery mildew to an incompatible one also in Arabidopsis.

SylA-induced transcriptome changes in infected and uninfected Arabidopsis

In order to monitor changes in the transcriptome after sylA application, 14-day-old Arabidopsis were infected with E. cichoracearum and sprayed with a $20 \mu \mathrm{M}$ sylA 


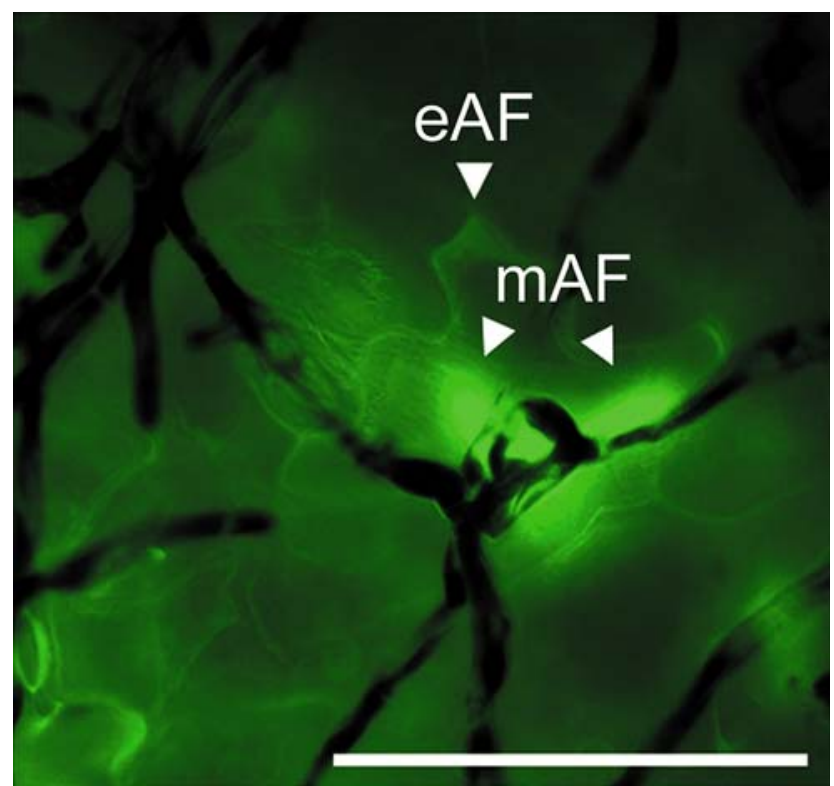

Fig. 2 Autofluorescence at infection sites on Arabidopsis leaves treated with sylA. Fourteen-day-old Arabidopsis plants infected with Erysiphe cichoracearum were treated with $20 \mu \mathrm{M}$ sylA $48 \mathrm{~h}$ after infection and photographed under fluorescent light $72 \mathrm{~h}$ after treatment. Cells emitted autofluorescence at infection sites. Accumulation of autofluorescing material was generally weaker in epidermal cells (eAF) than in the underlying mesophyll cells (mAF). Scale bar: $100 \mu \mathrm{m}$

solution or the control buffer solution. RNA was extracted from plants at $0.5,1,2,4,8$, and $12 \mathrm{~h}$ after treatment (hat) and equal amounts were pooled in pairs, resulting in an early pool ( 0.5 and 1 hat; referred to as IS1 for infected sylA-treated plants collected at 0.5 and 1 hat, respectively), a middle pool with RNA collected 2 and 4 hat (IS4), and a late pool from plant material collected 8 and 12 hat (IS12). For comparison, RNA was also extracted from uninfected sylA-treated plants 8 and 12 hat, which were pooled (S12). Fluorescently labeled probes derived from these RNA pools were hybridized to Affymetrix ATH1 whole genome gene chips. All experiments were repeated three times independently. The ratios of signal intensities corre- sponding to sylA-treated versus control-treated samples ( $\mathrm{t} / \mathrm{c}$-ratio) were calculated. The effect of powdery mildew infection alone on the transcriptome of Arabidopsis 56-60 hpi was calculated from the microarray hybridization data obtained with probes from infected versus non-infected plants sprayed with the control buffer solution in experiments IS12 and S12, respectively. The results are referred to as IC60 (infected and sprayed with control buffer 56 hpi and 60 hpi). Stringent criteria for data analysis were used. For statistical analysis, data were subjected to the parametric test using all available error estimates as implemented in the Genespring software and had to pass the false discovery rate multiple test correction (MTC) (Benjamini and Hochberg 1995). A $p$ cutoff value of 0.05 was chosen.

The results of these experiments in terms of numbers of genes whose transcripts significantly changed in abundance at least 2- and 3-fold, respectively, is given in Table 1. Surprisingly, reproducible sylA-dependent change of abundance could not be observed for any transcript in infected plants at the early time points up to 4 hat. While the abundance of hundreds of transcripts significantly increased in infected plants 8-12 hat, no transcript reproducibly decreased in abundance. In contrast, sylA application on uninfected Arabidopsis lead to the increase and decrease, respectively, in abundance of thousands of transcripts (Table 1). Thus, as in wheat, sylA appeared to have a larger effect on uninfected plants. Only 1 of the 455 transcripts accumulating in infected plants exhibited a significantly higher $\mathrm{t} / \mathrm{c}$-ratio than in uninfected plants (At5g14730; 1.9 -fold, $p \leq 0.05$ ). The 368 genes induced both in IS12 and S12 but not in IC60 (Fig. 3) exhibited an average ratio of $\mathrm{t} / \mathrm{c}$-ratios (IS12/S12) of $0.57 \pm 0.2$, which is significantly different from 1 ( $p<0.001$; onesample $t$-test). There is no indication that this is generally caused by a small induction $(<2)$ of these genes by the fungus alone and thus would represent an artefact caused by the chosen cut-off value of 2 for $\mathrm{t} / \mathrm{c}$-ratios, because the average of the product of

Table 1 Numbers of Arabidopsis genes differentially expressed upon sylA application

\begin{tabular}{|c|c|c|c|c|}
\hline \multirow[t]{2}{*}{ Experiment } & \multicolumn{4}{|c|}{ t/c-ratio } \\
\hline & $\geq 2$ & $\leq 0.5$ & $\geq 3$ & $\leq 0.333$ \\
\hline IS1 & 0 & 0 & 0 & 0 \\
\hline IS4 & 0 & 0 & 0 & 0 \\
\hline IS12 & 455 & 0 & 215 & 0 \\
\hline $\mathrm{S} 12$ & 2394 & 2873 & 1121 & 1760 \\
\hline I60 & 1045 & 996 & 555 & 275 \\
\hline
\end{tabular}

Data are derived from three independent experiments and passed Welch's $t$-test $(p \leq 0.05)$ including the Benjamini and Hochberg false discovery rate multiple testing correction (MTC) 


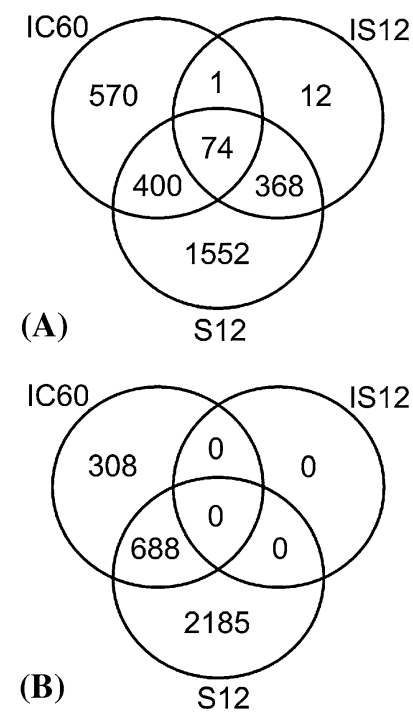

Fig. 3 Overlap of genes that respond to powdery mildew infection or to sylA treatment of uninfected and infected Arabidopsis plants. The diagram represents the distribution of genes at least 2-fold ( $p \leq 0.05$, MTC) induced (A) or repressed (B). IC60, powdery mildew infected plants 56-60 h after infection; IS12, 8-12 h after sylA spraying of plants infected with powdery mildew $48 \mathrm{~h}$ before sylA application; S12, uninfected plants $8-12 \mathrm{~h}$ after sylA application

corresponding t/c-ratios in IS12 and IC60 divided by the respective value in S12 over these 368 genes was $0.68 \pm 0.3$, again significantly different from 1 $(p<0.001)$. The corresponding value over all 1,920 $(1,552+368)$ genes activated by sylA alone (S12) but not the fungus alone (IC60) was $0.69 \pm 0.2(p<0.001)$. In contrast, this value over the 75 genes that were activated in experiments IS12 and IC60 (Fig. 3) was $1.08 \pm 0.6$, which is not significantly different from 1 $(p>0.5)$. Thus, in conclusion, it appears that in powdery mildew infected Arabidopsis, sylA indeed changed the activity of fewer genes to a lesser extent than in uninfected plants, similar to what was observed in wheat.

All but 13 of the 455 genes induced by sylA in infected plants were also included in the set of 2,394 genes induced in uninfected plants (Fig. 3). The 13 genes exclusively induced in infected plants all exhibit relatively low $\mathrm{t} / \mathrm{c}$-ratios not much above 2 (Table $\mathrm{S} 2$ ).

Figure 3 shows also the overlap between transcripts altered in abundance by powdery mildew infection (IC60) and sylA application (S12 and IS12), respectively. While none of the genes upregulated by powdery mildew alone was downregulated by sylA application on infected plants, 60 of these genes were downregulated by sylA spraying on uninfected plants. In contrast, three of the transcripts whose abundance was lowered by powdery mildew infection alone exhibited increased abundance after sylA application on infected tissue: At2g34930 (encoding an LRR protein; t/c-ratio 0.3 and 2.9 in IC60 and IS12, respectively), At1g07180 (internal NAD(P)H dehydrogenase, t/c-ratio 0.4 vs. 4.2), and At1g15180 (MATE efflux protein, t/c-ratio 0.3 vs. 8.9 ).

The microarray data were confirmed by RT-PCR with RNA from uninfected and infected plants 8-12 h after treatment with $20 \mu \mathrm{M}$ sylA or control buffer for At2g38340 (DREB subfamily A-2 of ERF/AP2 transcription factor family), At5g39820 (NAM family protein), At4g33070 (PDC1, pyruvate decarboxylase), and At1g17180 (glutathione $S$-transferase; GSTU25) (data not shown). In addition, transgenic plants were constructed carrying promoter-GUS reporter genes with promoter fragments of At2g38340, At5g39820, and At2g35980 (HIN1-like). These plants also confirmed the sylA-induction of the corresponding genes (data not shown).

Products of sylA-affected Arabidopsis genes

Transcripts whose abundance was changed more than 2-fold by sylA spraying were grouped according to gene ontology (GO) terms. A list ordered according to GO terms of all genes differentially expressed in S12 (>3-fold) and IS12 (>2-fold) is presented in supplementary Table S3. In order to interpret the results in terms of biological function, sylA-affected genes were analyzed using the MapMan tool (Thimm et al. 2004). With regard to genes involved in metabolism, sylA lowered the abundance of most corresponding transcripts in uninfected plants (Fig. 4A; Table S3, row 20 ff). This included transcripts encoding pectin esterases, cell wall modifying and degrading enzymes, and enzymes involved in cellulose synthesis, starch synthesis and starch degradation, lipid metabolism, C1 metabolism, sulfate assimilation, and proteins involved in light reactions (Fig. 4A, Table S3). Expression of genes involved in secondary metabolism (e.g., synthesis of phenylpropanoid, flavonoids, and terpenes) was also mostly reduced to a large extent (Fig. 4A; Table S3, row $290 \mathrm{ff}$ ). In contrast, strongly accumulating transcripts encoded proteins involved in mitochondrial electron transport like alternative oxidases (At3g22370, At3g22360, At1g32350) and both internal and external NADH dehydrogenases (At1g07180, At2g20800) as well as a number of glycolytic and fermentative enzymes (Table S3, row $456 \mathrm{ff}$ ). Transcripts encoding pyruvate decarboxylase 1 (At4g33070), which belongs to the latter group, showed a 656-fold increase in abundance in experiment S12 (240-fold in IS12). Strongly induced were also two genes encoding 

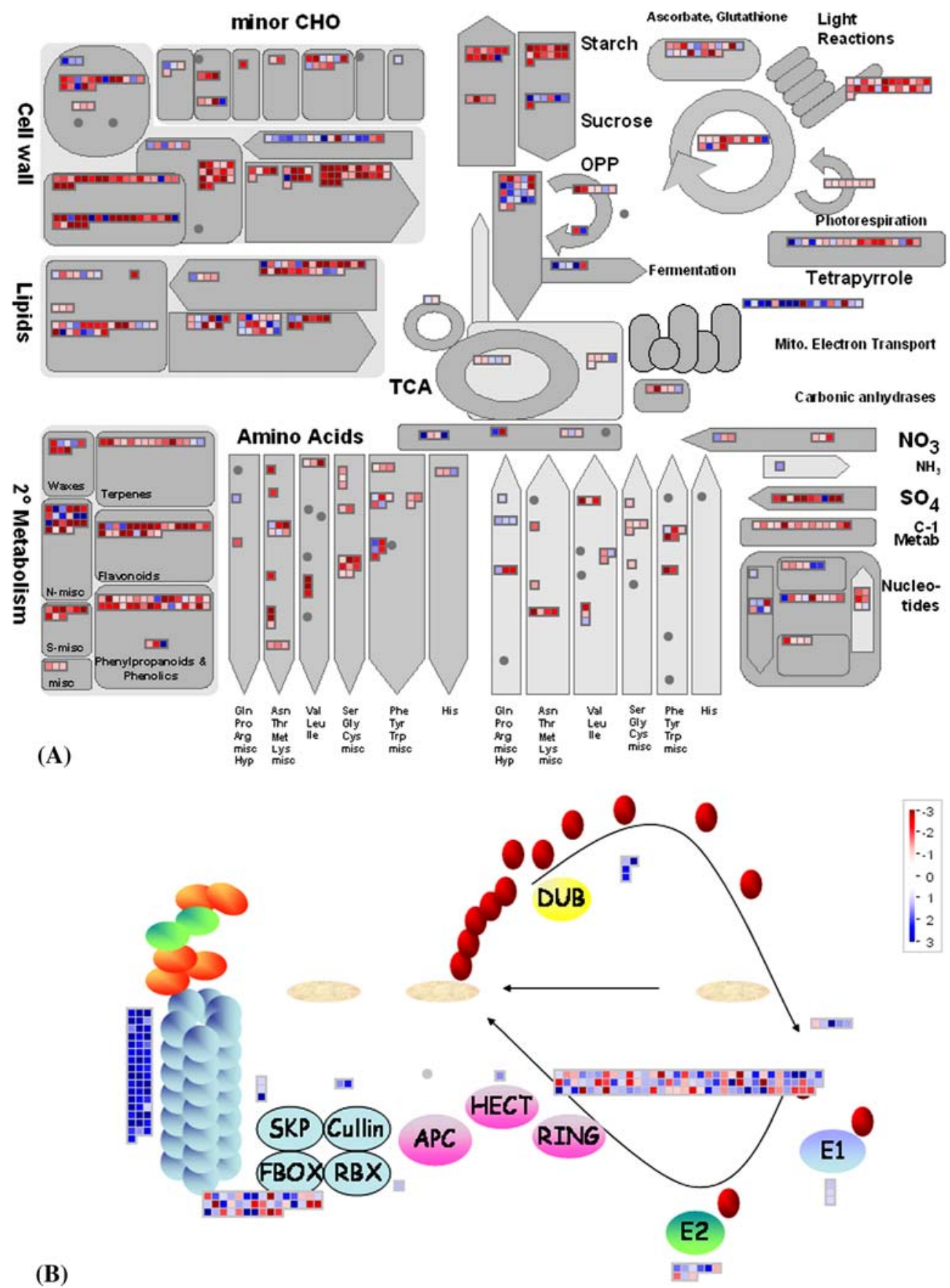

(B)

Fig. 4 Effect of sylA treatment on Arabidopsis genes involved in metabolism and proteasomal protein degradation. (A) The MapMan 'Metabolism Overview' display of the genes responding to sylA treatment of uninfected plants at the 8-12 hat time point (S12). (B) MapMan 'Proteasome' of the same data set used

glutamate decarboxylase (central amino acid metabolism), while genes coding for amino acid synthesis and degradation enzymes were mostly repressed (Fig. 4A; Table S3, row $170 \mathrm{ff}$ ). In infected plants (IS12), transcripts belonging to the same classes accumulated as in uninfected plants, although to a lesser extent and in much smaller numbers. in (A) for genes involved in the proteasomal protein degradation pathway. For both panels the color indicates the average fold change in $\log _{2}$ units according to the scale presented in the top right corner of (B). Repression is indicated by red (saturation at $\log _{2}=-3$ ), induction by blue (saturation at $\log _{2}=3$ )

With regard to cellular regulation, many genes involved in hormone signaling and response were downregulated by sylA action on uninfected plants, in particular those connected to auxin (Table S3, row $904 \mathrm{ff}$ ), whereas some genes involved in absisic acid and ethylene signaling or response were strongly induced (Table S3, row $951 \mathrm{ff}$ ). A strong response to sylA in 


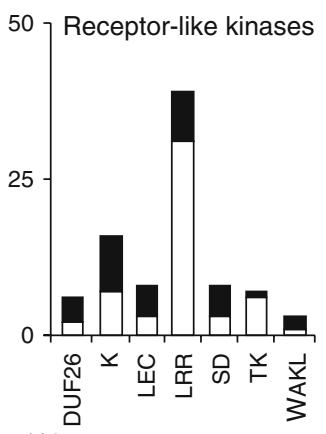

(A)

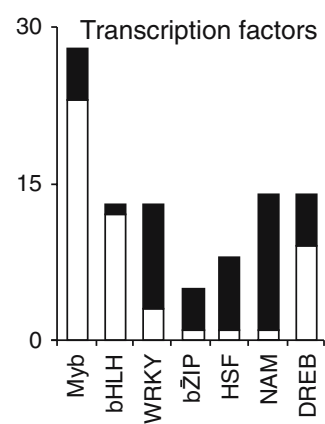

(B)

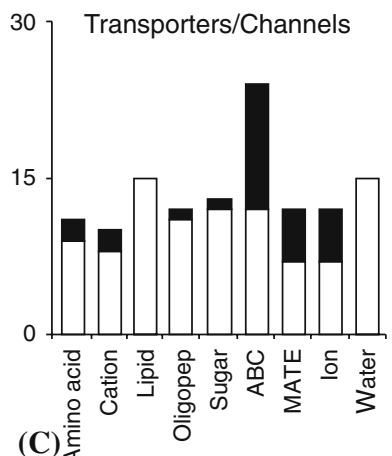

(C) $\frac{\mathrm{g}}{\mathrm{\varepsilon}}$

grouped according to their extracellular domains. DUF26, domain of unknown function; $\mathrm{K}$, kinase domain with no predicted signal motif; LEC, legume lectin; LRR, leucine-rich repeat; SD, S-locus glycoprotein; TK, transmembrane/kinase with no predicted signal motif; WAKL, wall-associated kinaselike

proteins, transporters for amino acids, cations, oligopeptides, and sugars, as well proteins forming water channels (Fig. 5C; Table S3, row $1565 \mathrm{ff}$ ). A number of genes encoding $\mathrm{ABC}$ transporters and MATE efflux proteins were strongly induced while other genes of these classes were down-regulated. Strongly accumulating were also transcripts encoding proteins involved in intracellular transport, such as nuclear importin $\alpha-1$ and $\alpha-2$ (At3g06720, At4g02150; Table S3, row 1683, 1684), which mediate nuclear transport, as well as TIM17-1 and TOM20-4 (At1g20350 and At5g40930; Table S3, row 1660, 1661), mitochondrial translocases in the inner and outer membrane, and a putative chloroplast import component (At4g03320; Table S3, row 1671). A number of genes related to vesicle trafficking were also up-regulated (Table S3, row $1764 \mathrm{ff}$ ). This included membrane associated family proteins known as SNAREs which play a role in membrane fusion and are central to the process of secretory vesicle targeting (Bock et al. 2001).

\section{Discussion}

Because sylA was topically applied by spraying, one may have expected stronger transcript accumulation in the epidermis in the wheat experiments. However, sylA is very hydrophilic as it is soluble in water but not in organic solvents such as e.g., methanol. Thus, the compound most likely cannot penetrate the cuticle but probably enters the leaf through stomata. This is supported by the observation that sylA must be applied in $0.05 \%$ Tween 20 to induce HR in colonized cells, which it does also in a translaminar fashion (Wäspi et al. 2001) and may explain why micromolar concentrations

transport processes decreased in abundance after sy treatment. This particularly concerned lipid transfer 
are needed to be effective by spray application but a 1,000-fold lower concentration was enough to saturate Pir $7 b$ esterase transcript accumulation in cultured rice cells (Hassa et al. 2000).

Microarray hybridization signal comparisons between powdery mildew-infected and uninfected syringolin-treated wheat and Arabidopsis was carried out in order to identify genes whose trascriptional activation correlated with the induction of the HR in colonized epidermal cells. Unexpectedly, in wheat no gene was identified whose transcripts accumulated exclusively in infected tissue after sylA treatment, i.e. correlated with the occurrence of the HR. In Arabidopsis however, 13 transcripts were identified that rather weakly but exclusively accumulated in infected tissue treated with sylA (Table S2). Apart from transcripts encoding proteins with unknown biological functions and some other proteins, two encoded an LRR disease resistance-like protein (At2g34930) and the WRKY75 transcription factor, respectively (At5g13080). Interestingly, the WRKY75 transcription factor was reported to have a role during $\mathrm{H}_{2} \mathrm{O}_{2}$-mediated programmed cell death (PCD) (Gechev et al. 2005) and was upregulated during PCD cell death triggered in Arabidopsis by the fungal AAL-toxin (Gechev et al. 2004). However, as WRKY75 transcripts accumulated 28 -fold over the control by powdery mildew infection alone (IC60), it seems unlikely that the further accumulation by a factor of 2.3 caused by sylA-application was causally related to the triggering of HR. Although it is possible that some of these 13 genes are involved in HR induction, we think it unlikely and favor another hypothesis (see below).

SylA application on uninfected Arabidopsis lead to a surprisingly large change in the transcriptome. Comparison of our data to publicly available Arabidopsis whole genome microarray hybridization data revealed overlaps of different degrees of the sylA response with various experimental treatments. Particularly interesting are the experiments reported by Thilmony et al. (2006), because they allowed the authors to discriminate between genes regulated by pathogen-associated molecular patterns (PAMP) and hrp-regulated virulence factors like type III secretion system (TTSS) effectors and coronatine in the interaction of wild-type and mutant $P$. syringae pv. tomato DC3000 strains with Arabidopsis. Of the 201 PAMP-induced genes reported, 58 were also affected by sylA, most of them induced (among them 14 protein kinases), but 14 repressed (including transcripts encoding WRKY7 and WRKY47 (At4g24240, At4g01720)). Of the 269 PAMP repressed genes, 193 were also repressed by sylA, while one encoding a MATE efflux transporter was induced.
Repressed genes included many cell wall-related enzymes and proteins and a number of auxin responsive proteins. Of the 275 TTSS-induced genes, 87 were induced and 23 were repressed by sylA, while of the 516 TTSS-repressed genes, 236 were repressed also by sylA (including histone genes) and 11 were induced, including the WRKY30 gene (At5g24110, 130-fold). Interestingly, of the 597 coronatine-induced genes, 238 were affected by sylA, of which 200 were repressed, including jasmonate-related genes. Of 347 coronatinerepressed genes, 169 responded to sylA, all but 22 of which were also repressed. Thus, sylA appears to trigger transcriptome changes in Arabidopsis that have aspects of responses to PAMPs as well as effects of virulence factors. This is also suggested by the analysis of publicly available triplicate chip hybridization experiments (NASCArrays-120) that compared the response of Arabidopsis to $P$. syringae pv. tomato DC3000 (compatible interaction) and to the same strain expressing avrRpm1, which causes gene-for-gene resistance (incompatible interaction). In the compatible interaction, 642 induced genes ( $>2$-fold, $p<0.05$, MTC) overlapped with sylA-induced genes, among them 19 proteasome subunit genes and a number of other genes related to the ubiquitin pathway, a number of heat shock genes, two alternative oxidase genes, and many TFs genes, including At2g38340, which is 530-fold induced by sylA and encodes a DREB A-2 family protein. While the overlap with genes induced in the incompatible interaction is somewhat smaller (547 genes, among the missing ones are most genes related to the proteasomal degradation pathway), the difference is more pronounced with regard to repressed genes: 1186 sylA-repressed genes ( $>2$-fold, $p<0.05$, MTC) overlapped with genes repressed in the compatible interaction as compared to an overlap of 519 genes with the incompatible interaction. Thus the sylA response has more in common with transcriptome changes associated with the compatible interaction than with the incompatible interaction.

Interesting in this connection is also the observation that the accumulation of transcripts encoding a homolog of the DMI1 gene of Medicago trunculata is induced by sylA in wheat (At5g49960, the homolog in Arabidopsis, was not significantly affected by sylA). This gene was shown to be necessary for the interaction of host plants with symbiontic bacteria and fungi (Ané et al. 2004). Taken together, it is tempting to speculate that sylA acts as an effector of $P$. syringae pv. syringae that helps to put host plant cells into a physiological state from which the bacteria may profit. At present it is unclear whether and how the accumulation of transcripts related to the proteasomal degradation 
pathway may contribute to this. Of course, the sylA used in this study was produced by strain B301D-R, which was isolated from bean ( $\mathrm{Xu}$ and Gross 1988). However, $P$. syringae pv. syringae is a ubiquitous epiphytic bacterium inhabiting the phyllosphere of many plant species, including wheat (Quigley and Gross 1994; Hirano and Upper 2000; Lindow and Brandl 2003; Marco et al. 2005), although it remains to be determined how widespread syringolin production within this taxon is.

Why is the sylA response in infected tissue weaker than in uninfected tissue?

A rather surprising phenomenon observed in both wheat and Arabidopsis experiments was that sylA application induced fewer genes to a lesser extent on infected plants as compared to uninfected plants. The apparent reduced sylA response in infected leaves may be considered to originate from inherent differences of the experimental setup, as e.g., the fact that colonized cells undergo HR in infected tissue, or the fact that control-treated infected leaves contain larger amounts of fungal tissue than sylAtreated leaves. Microscopic evaluation of the infection density showed that on average, about $15 \%$ of epidermal cells were colonized in our experiments, which form a proportion of less than $1 \%$ of all leaf cells (including the mesophyll). As we could not detect epidermis-specific accumulation of sylA-induced transcripts in wheat, and we assume this to be true also in Arabidopsis, this seems too small a proportion to cause the observed lower response. Thus, a possible explanation is that signals emanating from colonized cells undergoing HR and/or the fungal parasite itself cause neighboring cells to suppress the response of genes normally affected by sylA to a certain degree, thereby decreasing the proportion of fully responding cells. Indeed, evidence of suppression of defense-related genes and induction of susceptibility in cells neighboring cells colonized by powdery mildew has long been demonstrated in cereals (Kuno et al. 1985a, b, 1991; Carver et al. 1999; Lyngkjaer and Carver 1999; Wäspi et al. 2001) and also in dicots (for a reviews see Nomura et al. 2005; Chisholm et al. 2006). Thus, we hypothesize that the observed reduced transcriptional sylA response of powdery mildew-infected tissue may be due to a suppressive effect the fungus exerts in colonized and neighboring cells.

A hypothesis about sylA-induced cell death at infection sites

The transcriptional response of wheat to sylA is similar to the one expected after impairment of mitochondrial integrity and oxidative phosphorylation. The accumulation of transcripts coding for mitochondrial HSPs and chaperones may be viewed as a counteracting response of the plant. Indeed, transcripts encoding Hsp23.5 (OA_a1B01) and Hsp23.6 (OA_a1H02) were the only ones significantly accumulating more than 2-fold already $2 \mathrm{~h}$ after sylA application (data not shown). The strong induction of AOX transcripts suggests that AOX is needed, perhaps to counteract a high reduction state of the ubiquinol pool (and thus the generation of oxygen radicals) which may result from an unusually high NAD(P)H supply and/or the inhibition/dysfunction of the cytochrome pathway (reviewed in Moore et al. 2002; reviewed in Millenaar and Lambers 2003). That the $\mathrm{NAD}(\mathrm{P}) \mathrm{H}$ supply may be high is also indicated by the accumulation of transcripts encoding a putative external rotenone-insensitive $\mathrm{NAD}(\mathrm{P}) \mathrm{H}$ dehydrogenase. OA_a2B11 encodes a protein most similar to Arabidopsis NDB2, which likely is located on the external side of the inner membrane (Michalecka et al. 2003). While AOX provides a bypass for the cytochrome electron pathway, external and internal rotenone-insensitive $\mathrm{NAD}(\mathrm{P}) \mathrm{H}$ dehydrogenases provide a bypass for complex I electron flow and oxidation of cytoplasmic $\mathrm{NAD}(\mathrm{P}) \mathrm{H}$ without proton pumping, which is important for continued glycolysis and continuation of the TCA in the absence of a functional cytochrome electron pathway (reviewd by Rasmusson et al. 2004). Indeed, the accumulation of transcripts encoding sucrose degrading and nearly all glycolytic enzymes as well as three TCA enzymes suggests that sylA-treated cells try to compensate for the loss of energy supply due to impaired oxidative phosphorylation by increasing glycolysis. At the same time, metabolism seems to switch to alcoholic fermentation, as ADH1-encoding transcripts also accumulate. Fermentation permits regeneration of $\mathrm{NAD}^{+}$for the maintenance of ATP generation by glycolysis under low oxygen conditions (reviewed in Geigenberger 2003). The accumulation of transcripts encoding proteins similar to alanine aminotransferase (OA_a2D10) and aspartate aminotransferase (OA_b2F07) may also be viewed in the context of fermentation, as they catalyse the production of alanine from pyruvate and $\gamma$-aminobutyrate from $\alpha$-ketoglutarate. Both compounds are known to accumulate during anoxia and might counteract cytosolic acidification during anoxia. Thus, they are thought to significantly contribute to anoxia stress tolerance (Geigenberger 2003; Ricoult et al. 2005).

Although the observable sylA-induced changes of the transcriptome in Arabidopsis were far greater than in wheat, the interpretation developed above for wheat 
holds true also for Arabidopsis. Transcripts encoding HSPs (many of them mitochondrial), AOX, internal and external $\mathrm{NAD}(\mathrm{P}) \mathrm{H}$ oxidases, and other mitochondrial proteins accumulate after sylA treatment, as do transcripts encoding glycolytic and fermentation enzymes. Thus, responses of wheat and Arabidopsis to sylA are similar in this respect, including the accumulation of transcripts encoding components of the proteasomal degradation pathway.

Why does sylA trigger HR in powdery mildew-colonized cells? If the picture developed above reflects some truth, then HR may be the result of the parasiteinduced suppression of the transcriptional response in colonized and neighboring cells, which may lead to insufficient production of the protective proteins discussed above. This would prevent recovery of these cells from whatever the insult imposed by sylA is, and thus would lead to cell death. At present this hypothesis remains speculative, as HR could be triggerd by the synergistic combination of any consequence of fungal invasion and syringolin treatment. We have initiated a screen of mutagenized Arabidopsis populations for mutants that no longer react with HR at powdery mildew infection sites after sylA application. We hope that the analysis of such mutants will help to elucidate the mode of action of syringolin.

Acknowledgements We thank E.E. Farmer and P. Reymond, University of Lausanne, for use of the Gene Expression Laboratory Microarray facility at the Department of Plant Molecular Biology, U. Wagner and A. Patrignani, Functional Genomics Center Zurich, as well as T. Wicker for help with bioinformatics tasks, and R. Honegger for help with the identification of Erysiphe cichoracearum. Support by the Swiss National Science Foundation (grant 3100A0-100046), the Functional Genomics Center Zurich, and the Foundation for Scientific Research at the University of Zurich is greatfully acknowledged.

\section{References}

Amrein H, Makart S, Granado J, Shakya R, Schneider-Pokorny J, Dudler R (2004) Functional analysis of genes involved in the synthesis of syringolin A by Pseudomonas syringae pv. syringae B301D-R. Mol Plant-Microb Interact 17:90-97

Ané JM, Kiss GB, Riely BK, Penmetsa RV, Oldroyd GED, Ayax C, Levy J, Debelle F, Baek JM, Kalo P, Rosenberg C, Roe BA, Long SR, Denarie J, Cook DR (2004) Medicago truncatula DMI1 required for bacterial and fungal symbioses in legumes. Science 303:1364-1367

Ashburner M, Ball CA, Blake JA, Botstein D, Butler H, Cherry JM, Davis AP, Dolinski K, Dwight SS, Eppig JT, Harris MA, Hil DP, Issel-Tarver L, Kasarskis A, Lewis S, Matese JC, Richardson JE, Ringwald M, Rubin GM, Sherlock G (2000) Gene Ontology: Tool for the unification of biology. Nat Genet 25:25-29
Banerjee J, Ghosh S (2004) Bax increases the pore size of rat brain mitochondrial voltage-dependent anion channel in the presence of tBid. Biochem Biophys Res Commun 323:310 314

Benjamini Y, Hochberg Y (1995) Controlling the false discovery rate - a practical and powerful approach to multiple testing. J Roy Stat Soc B Met 57:289-300

Benz R (1994) Permeation of hydrophilic solutes through mitochondrial outer membranes-review on mitochondrial porins. Biochim Biophys Acta-Rev Biomembranes 1197: 167-196

Bock JB, Matern HT, Peden AA, Scheller RH (2001) A genomic perspective on membrane compartment organization. Nature 409:839-841

Bruggmann R, Abderhalden O, Reymond P, Dudler R (2005) Analysis of epidermis- and mesophyll-specific transcript accumulation in powdery mildew-inoculated wheat leaves. Plant Mol Biol 58:247-267

Carver TLW, Lyngkjaer MF, Neyron L, Strudwicke CC (1999) Induction of cellular accessibility and inaccessibility and suppression and potentiation of cell death in oat attacked by Blumeria graminis f.sp. avenae. Physiol Molec Plant Pathol 55:183-196

Chisholm ST, Coaker G, Day B, Staskawicz BJ (2006) Hostmicrobe interactions: shaping the evolution of the plant immune response. Cell 124:803-814

Crompton M, Barksby E, Johnson N, Capano M (2002) Mitochondrial intermembrane junctional complexes and their involvement in cell death. Biochimie 84:143-152

Diatchenko L, Lukyanov S, Lau YFC, Siebert PD (1999) Suppression subtractive hybridization: A versatile method for identifying differentially expressed genes. In: cDNA preparation and characterization. Academic Press Inc, San Diego, pp 349-380

Dudoit S, Yang YH, Callow MJ, Speed TP (2002) Statistical methods for identifying differentially expressed genes in replicated cDNA microarray experiments. Stat Sin 12:111139

Gechev TS, Gadjev IZ, Hille J (2004) An extensive microarray analysis of AAL-toxin-induced cell death in Arabidopsis thaliana brings new insights into the complexity of programmed cell death in plants. Cell Mol Life Sci 61:11851197

Gechev TS, Minkov IN, Hille J (2005) Hydrogen peroxide-induced cell death in Arabidopsis: Transcriptional and mutant analysis reveals a role of an oxoglutarate-dependent dioxygenase gene in the cell death process. Iubmb Life 57:181188

Geigenberger P (2003) Response of plant metabolism to too little oxygen. Curr Opin Plant Biol 6:247-256

Hamilton EW, Heckathorn SA (2001) Mitochondrial adaptations to $\mathrm{NaCl}$. Complex I is protected by anti-oxidants and small heat shock proteins, whereas complex II is protected by proline and betaine. Plant Physiol 126:1266-1274

Hassa P, Granado J, Freydl E, Wäspi U, Dudler R (2000) Syringolin-mediated activation of the Pir7b esterase gene in rice cells is suppressed by phosphatase inhibitors. Mol PlantMicrob Interact 13:342-346

Hengartner MO (2000) The biochemistry of apoptosis. Nature 407:770-776

Hirano SS, Upper CD (2000) Bacteria in the leaf ecosystem with emphasis on Pseudomonas syringae-a pathogen, ice nucleus, and epiphyte. Microbiol Mol Biol Rev 64:624-653 
Hrabak EM, Willis DK (1992) The lemA gene required for pathogenicity of Pseudomonas syringae pv. syringae on bean is a member of a family of 2-component regulators. $\mathrm{J}$ Bacteriol 174:3011-3020

Hrabak EM, Willis DK (1993) Involvement of the IemA gene in production of syringomycin and protease by Pseudomonas syringae pv. syringae. Mol Plant-Microb Interact 6:368-375

Hubbell E, Liu WM, Mei R (2002) Robust estimators for expression analysis. Bioinformatics 18:1585-1592

Hughes TR, Mao M, Jones AR, Burchard J, Marton MJ, Shannon KW, Lefkowitz SM, Ziman M, Schelter JM, Meyer MR, Kobayashi S, Davis C, Dai HY, He YDD, Stephaniants SB, Cavet G, Walker WL, West A, Coffey E, Shoemaker DD, Stoughton R, Blanchard AP, Friend SH, Linsley PS (2001) Expression profiling using microarrays fabricated by an inkjet oligonucleotide synthesizer. Nat Biotechnol 19:342-347

Kuno H, Kuroda H, Hayashimoto A, Ishizaki H (1985a) Induced susceptibility and enhanced resistance at the cellular level in barley coleoptiles. II. Timing and localization of induced sysceptibility in a single coleptile cell and its transfer to an adjacent cell. Can J Bot 64:889-895

Kuno H, Hayashimoto A, Harui M, Ishizaki H (1985b) Induced susceptibility and enhanced resistance at the cellular level in barley coleoptiles. I. The significance of timing of fungal invasion. Physiol Plant Pathol 27:43-54

Kuno H, Kuroda H, Toyoda K, Yamaoka N, Kobayashi I (1991) Induced susceptibility and enhanced resistance at the cellular level in barley coleoptiles. IX. Accessibility induced by Erysiphe graminis which promotes the subsequent infection of challenging E. graminis. Ann Phytopathol Soc Jpn 57:5760

Lemeshko VV (2002) Model of the outer membrane potential generation by the inner membrane of mitochondria. Biophys J 82:684-692

Lemeshko VV, Lemeshko SV (2004) The voltage-dependent anion channel as a biological transistor: Theoretical considerations. Eur Biophys J Biophys Lett 33:52-359

Lindow SE, Brandl MT (2003) Microbiology of the phyllosphere. Appl Environ Microbiol 69:1875-1883

Liu WM, Mei R, Di X, Ryder TB, Hubbell E, Dee S, Webster TA, Harrington CA, Ho MH, Baid J, Smeekens SP (2002) Analysis of high density expression microarrays with signedrank call algorithms. Bioinformatics 18:1593-1599

Lyngkjaer MF, Carver TLW (1999) Induced accessibility and inaccessibility to Blumeria graminis f.sp hordei in barley epidermal cells attacked by a compatible isolate. Physiol Molec Plant Pathol 55:151-162

Maniatis T, Fritsch EF, Sambrook J (1982) Molecular Cloning. A Laboratory Manual. Cold Spring Harbor Laboratory Press, Cold Spring Harbor

Marco ML, Legac J, Lindow SE (2005) Pseudomonas syringae genes induced during colonization of leaf surfaces. Environ Microbiol 7:1379-1391

Meiners S, Heyken D, Weller A, Ludwig A, Stangl K, Kloetzel PM, Kruger E (2003) Inhibition of proteasome activity induces concerted expression of proteasome genes and de Novo formation of mammalian proteasomes. J Biol Chem 278:21517-21525

Michalecka AM, Svensson AS, Johansson FI, Agius SC, Johanson U, Brennicke A, Binder S, Rasmusson AG (2003) Arabidopsis genes encoding mitochondrial type IIN$\mathrm{AD}(\mathrm{P}) \mathrm{H}$ dehydrogenases have different evolutionary orgin and show distinct responses to light. Plant Physiol 133:642652

Millenaar FF, Lambers H (2003) The alternative oxidase: In vivo regulation and function. Plant Biol 5:2-15
Moon J, Parry G, Estelle M (2004) The ubiquitin-proteasome pathway and plant development. Plant Cell 16:3181-3195

Moore AL, Albury MS, Crichton PG, Affourtit C (2002) Function of the alternative oxidase: is it still a scavenger? Trends Plant Sci 7:478-481

Nomura K, Melotto M, He SY (2005) Suppression of host defense in compatible plant-Pseudomonas syringae interactions. Curr Opin Plant Biol 8:361-368

Quigley NB, Gross DC (1994) Syringomycin production among strains of Pseudomonas syringae pv. syringae: conservation of the syrB and syrD genes and activation of phytotoxin production by plant signal molecules. Mol Plant-Microb Interact 7:78-90

Randolph JB, Waggoner AS (1997) Stability, specificity and fluorescence brightness of multiply-labeled fluorescent DNA probes. Nucleic Acids Res 25:2923-2929

Rasmusson AG, Soole KL, Elthon TE (2004) Alternative $\mathrm{NAD}(\mathrm{P}) \mathrm{H}$ dehydrogenases of plant mitochondria. Annu Rev Plant Biol 55:23-39

Reimmann C, Hofmann C, Mauch F, Dudler R (1995) Characterization of a rice gene induced by Pseudomonas syringae pv. Syringae-requirement for the bacterial lemA genefunction. Physiol Molec Plant Pathol 46:71-81

Ricoult C, Cliquet JB, Limami AM (2005) Stimulation of alanine amino transferase (AlaAT) gene expression and alanine accumulation in embryo axis of the model legume Medicago truncatula contribute to anoxia stress tolerance. Physiol Plant 123:30-39

Rocke DM, Durbin B (2001) A model for measurement error for gene expression arrays. J Comput Biol 8:557-569

Rostovtseva T, Colombini M (1997) VDAC channels mediate and gate the flow of ATP: Implications for the regulation of mitochondrial function. Biophys J 72:1954-1962

Saeed AI, Sharov V, White J, Li J, Liang W, Bhagabati N, Braisted J, Klapa M, Currier T, Thiagarajan M, Sturn A, Snuffin M, Rezantsev A, Popov D, Ryltsov A, Kostukovich E, Borisovsky I, Liu Z, Vinsavich A, Trush V, Quackenbush J. 2003. TM4: A free, open-source system for microarray data management and analysis. Biotechniques 34:374-378

Scharf KD, Siddique M, Vierling E (2001) The expanding family of Arabidopsis thaliana small heat stress proteins and a new family of proteins containing alpha-crystallin domains (Acd proteins). Cell Stress Chaperon 6:225-237

Schweizer P, Christoffel A, Dudler R (1999) Transient expression of members of the germin-like gene family in epidermal cells of wheat confers disease resistance. Plant $\mathbf{J}$ 20:540-552

Shimizu S, Ide T, Yanagida T, Tsujimoto Y (2000) Electrophysiological study of a novel large pore formed by Bax and the voltage-dependent anion channel that is permeable to cytochrome c. J Biol Chem 275:12321-12325

Smalle J, Vierstra RD (2004) The ubiquitin 26S proteasome proteolytic pathway. Annu Rev Plant Biol 55:555-590

Staden R (1996) The Staden sequence analysis package. Mol Biotechnol 5:233-241

Thilmony R, Underwood W, He SY (2006) Genome-wide transcriptional analysis of the Arabidopsis thaliana interaction with the plant pathogen Pseudomonas syringae pv. tomato DC3000 and the human pathogen Escherichia coli O157: H7. Plant J 46:34-53

Thimm O, Blasing O, Gibon Y, Nagel A, Meyer S, Kruger P, Selbig J, Muller LA, Rhee SY, Stitt M (2004) MAPMAN: a user-driven tool to display genomics data sets onto diagrams of metabolic pathways and other biological processes. Plant J 37:914-939 
Tör M, Yemm A, Holub E (2003) The role of proteolysis in $R$ gene mediated defence in plants. Mol Plant Pathol 4:287-296

Vierstra RD (2003) The ubiquitin/26S proteasome pathway, the complex last chapter in the life of many plant proteins. Trends Plant Sci 8:135-142

Wäspi U, Schweizer P, Dudler R (2001) Syringolin reprograms wheat to undergo hypersensitive cell death in a compatible interaction with powdery mildew. Plant Cell 13:153-161

Wäspi U, Blanc D, Winkler T, Ruedi P, Dudler R (1998a) Syringolin, a novel peptide elicitor from Pseudomonas syringae pv. syringae that induces resistance to Pyricularia oryzae in rice. Mol Plant-Microbe Interact 11:727-733

Wäspi U, Hassa P, Staempfli AA, Molleyres LP, Winkler T, Dudler R (1999) Identification and structure of a family of syringolin variants: Unusual cyclic peptides from Pseudomonas syringae pv. syringae that elicit defense responses in rice. Microbiol Res 154:89-93

Wäspi U, Misteli B, Hasslacher M, Jandrositz A, Kohlwein SD, Schwab H, Dudler R (1998b) The defense-related rice gene
Pir7b encodes an alpha/beta hydrolase fold protein exhibiting esterase activity towards naphthol AS-esters. Eur J Biochem 254:32-37

Xu GW, Gross DC (1988) Physical and functional analyses of the $s y r A$ and $s y r B$ genes involved in syringomycin production by Pseudomonas syringae pv. syringae. J Bacteriol 170:56805688

Yahiaoui N, Srichumpa P, Dudler R, Keller B (2004) Genome analysis at different ploidy levels allows cloning of the powdery mildew resistance gene $P m 3 b$ from hexaploid wheat. Plant J 37:528-538

Yang PZ, Fu HY, Walker J, Papa CM, Smalle J, Ju YM, Vierstra RD (2004) Purification of the Arabidopsis 26 S proteasome-Biochemical and molecular analyses revealed the presence of multiple isoforms. J Biol Chem 279:6401-6413

Yang YH, Dudoit S, Luu P, Lin DM, Peng V, Ngai J, Speed TP (2002) Normalization for cDNA microarray data: a robust composite method addressing single and multiple slide systematic variation. Nucleic Acids Res 30(4):e15 